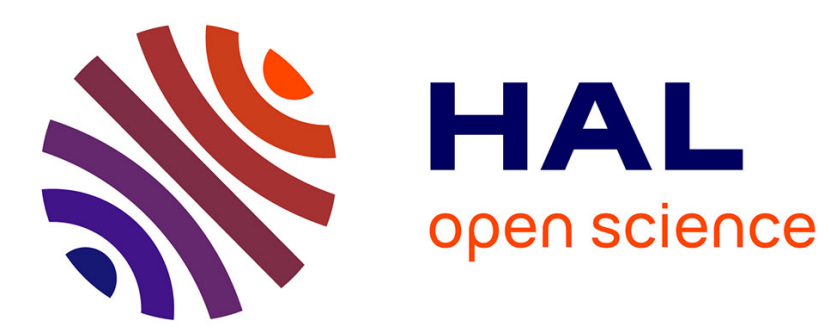

\title{
EIN2, the central regulator of ethylene signalling, is localised at the ER membrane where it interacts with the ethylene receptor ETR1
}

\author{
Melanie Ma Bisson, Andrea Bleckmann, Silke Allekotte, Georg Groth
}

\section{- To cite this version:}

Melanie Ma Bisson, Andrea Bleckmann, Silke Allekotte, Georg Groth. EIN2, the central regulator of ethylene signalling, is localised at the ER membrane where it interacts with the ethylene receptor ETR1. Biochemical Journal, 2009, 424 (1), pp.1-6. 10.1042/BJ20091102 . hal-00479232

\section{HAL Id: hal-00479232 \\ https://hal.science/hal-00479232}

Submitted on 30 Apr 2010

HAL is a multi-disciplinary open access archive for the deposit and dissemination of scientific research documents, whether they are published or not. The documents may come from teaching and research institutions in France or abroad, or from public or private research centers.
L'archive ouverte pluridisciplinaire HAL, est destinée au dépôt et à la diffusion de documents scientifiques de niveau recherche, publiés ou non, émanant des établissements d'enseignement et de recherche français ou étrangers, des laboratoires publics ou privés. 


\title{
EIN2, THE CENTRAL REGULATOR OF ETHYLENE SIGNALLING, IS LOCALISED AT THE ER MEMBRANE WHERE IT INTERACTS WITH THE ETHYLENE RECEPTOR ETR1
}

\author{
Melanie M. A. BISSON*, Andrea BLECKMANN†, Silke ALLEKOTTE* and \\ Georg GROTH*§
}

*Department of Plant Biochemistry, Heinrich-Heine University, 40225 Düsseldorf, Universitätsstr. 1, Germany, †Department of Genetics, Heinrich-Heine University, 40225 Düsseldorf, Universitätsstr. 1, Germany,

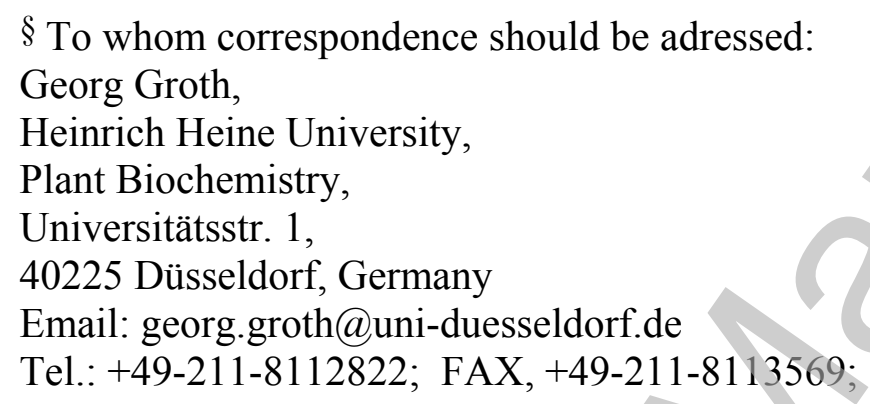

$\S$ To whom correspondence should be adressed:

Georg Groth,

Heinrich Heine University,

Plant Biochemistry,

Universitätsstr. 1,

40225 Düsseldorf, Germany

Email: georg.groth@uni-duesseldorf.de

Tel.: +49-211-8112822; FAX, +49-211-8113569;

Short title: Subcellular colocalisation and specific interaction of Arabidopsis EIN2 and ETR1

Keywords: Plant hormone, Ethylene signalling, membrane protein, EIN2, protein-protein interaction, fluorescence spectroscopy

List of Abbreviations: CTR1 constitutive triple response 1; EIN2 ethylene insensitive 2; ETR ethylene resistant; ERS ethylene response sensor; GFP green fluorescent protein; Ni-IDA nickel iminodiacetic acid; IPTG isopropyl-1-thio- $\beta$-Dgalactopyranoside; PMSF phenylmethylsulfonyl fluoride; SDS sodium dodecyl sulfate; PAGE polyacrylamide gel electrophoresis; SDS sodium dodecyl sulphate; $\mathrm{TMH}$ transmembrane helix; Tris tris-(hydroxymethyl)-aminomethane. 


\begin{abstract}
Genetic studies have identified the membrane protein Ethylene Insensitive 2 (EIN2) as a central component of ethylene signalling in Arabidopsis. In addition, EIN2 might take part in multiple hormone signalling pathways and in responses to pathogens as demonstrated by recent genetic and biochemical studies. Here we show, by an integrated approach of in vivo and in vitro fluorescence techniques, that EIN2 is localised at the ER membrane where it shows specific interaction with the ethylene receptor protein ETR1.
\end{abstract}




\section{INTRODUCTION}

The gaseous hormone ethylene regulates a diverse and complex range of developmental processes in plants but is also involved in mediating responses to various biotic and abiotic stresses [1, 2]. Based on reverse genetics several components involved in ethylene signalling have been identified in Arabidopsis thaliana. According to these studies ethylene is perceived by a family of integral membrane receptors (ETR1, ETR2, ERS1, ERS2, EIN4) which are similar to bacterial two-component histidine kinases [3-6]. However, in contrast to these receptors that are found in the bacterial plasma membrane the ethylene receptors are located at the endoplasmic reticulum $[7,8]$. The ethylene receptors activate CTR1, a soluble protein kinase which co-localises with the receptors at the ER membrane [9] and which negatively regulates downstream components in the ethylene signalling pathway [10]. EIN2, an integral membrane protein acting downstream of CTR1, seems to play a central role in ethylene signalling as EIN2 is the only gene of all components involved in the ethylene pathway whose loss-of-function mutations lead to complete ethylene insensitivity [11]. Although the central role of EIN2 for ethylene signalling is broadly recognized, current knowledge on this part of the ethylene signalling pathway is still limited. The localisation of EIN2 in the plant cell is not known yet. Furthermore, the molecular mechanism of signalling to and from EIN2 is largely unknown. Recent data of Qiao et al. [12] showing that degradation of EIN2 is triggered by the ethylene-controlled F-box proteins ETP1 and ETP2 provide the first important clue to unravel the complex role of EIN 2 in plant hormone signalling.

In this study we have probed the intracellular localisation of EIN2 by fluorescence spectroscopy and have identified an unexpected interaction of this central protein of the ethylene signalling cascade. This interaction has not been found in previous genetic studies. The integrated approach of in planta and in vitro fluorescence measurements presented in this study provides a detailed picture on protein-protein interactions in signalling networks - first by unravelling the intracellular localisation of the complex and second by providing precise thermodynamic parameter on the complex. 


\section{EXPERIMENTAL}

\section{Cloning and transient expression of EIN2 and ETR1 in Nicotiana benthamiana}

The cDNA fragments encoding the genes for EIN2 or ETR1 were transferred via the Gateway BP-reaction into donor vector pDONR201 (Invitrogen GmbH, Karlsruhe). Plant expression vectors encoding ETR1 or EIN2, respectively, were generated via Gateway LR-reaction (Invitrogen) using C-terminal GFP- or mCherry-tagged destination vectors $p A B i n d G F P$ and $p A B i n d m C h e r r y$ that are based on vector $\mathrm{pMDC} 7$ [13]. Expression vectors (pABindGFP-EIN2, pABindGFP-ETR1) and $p A B i n d m C h e r r y-E I N 2)$ as well as vector $p E R-R b$ encoding a ER-marker protein [14] were transfected in Agrobacterium tumefaciens strain GV3101 pMP90 [15]. Bacterial cells were resuspended in AS-Medium $(5 \%(\mathrm{w} / \mathrm{v})$ sucrose, $100 \mathrm{mg}$ magnesium sulfate and glucose, $0.01 \%$ Silwet L77 and $0.225 \mathrm{mM}$ Acetosyringon). For transformation, A. tumefaciens cells containing GFP- and mCherry-tagged expression vectors and cells containing p19-plasmid coding for the P19 protein of tomato bushy stunt virus [16] to suppress gene silencing were mixed at 1:1:1 ratio (all to OD600 $=0.4$ ) and infiltrated in 5 week old Nicotiana benthamiana leafs. Infiltrated leafs were treated 36 $\mathrm{h}$ after transformation with $25 \mu \mathrm{M}$ of proteasome inhibitor MG-132 and protein expression was induced by adding $20 \mu \mathrm{M} \beta$-Estradiol in $0.1 \%$ TWEEN 20 .

\section{Cloning, expression and purification of EIN2 and ETR1 in Escherichia coli}

The DNA fragment encoding the membrane-extrinsic carboxyl-terminal domain of EIN2 (EIN2 ${ }^{479-1294}$ ) was amplified from a cDNA library obtained from etiolated seedlings of Arabidopsis thaliana and cloned into expression vector pET21a (Novagen, Darmstadt, Germany) containing a modified multiple cloning site derived from pET28a (Novagen). Resulting plasmid pET21a_MCSpET28a_EIN2 ${ }^{479-1294}$ which encodes for the carboxyl-terminal part of EIN2 carrying amino-terminal and carboxyl-terminal hexahistidine-tags was transformed into the $E$. coli strain BL21(DE3) and cells were grown in 2 YT medium at $30^{\circ} \mathrm{C}$. Expression of EIN2 $2^{479-1294}$ was induced by addition of $0.5 \mathrm{mM}$ IPTG at an optical density of 0.8 . Cells were harvested $6 \mathrm{~h}$ after induction by centrifugation and stored at $-20^{\circ} \mathrm{C}$. For purification of EIN2 ${ }^{479-1294}$ cells were resuspended in $50 \mathrm{mM}$ potassium phosphate $\mathrm{pH} 7.6,5 \%(\mathrm{w} / \mathrm{v})$ glycerol, $300 \mathrm{mM}$ sodium chloride, $0.002 \%(\mathrm{w} / \mathrm{v})$ PMSF and passed through a precooled French pressure cell at 12,000 psi. After centrifugation of the cell lysate at $100,000 \mathrm{~g}$ the supernatant was applied on a Ni-IDA affinity column $(10 \mathrm{~mm}$ diameter x $200 \mathrm{~mm}$ length) previously equilibrated with $50 \mathrm{mM}$ potassium phosphate buffer $\mathrm{pH} 7.6,5 \%(\mathrm{w} / \mathrm{v})$ glycerol, $300 \mathrm{mM}$ sodium chloride, $0.002 \%(\mathrm{w} / \mathrm{v}) \mathrm{PMSF}$. The column was washed with 3 bed volumes of the same buffer containing $0 \mathrm{mM}, 75 \mathrm{mM}$ and $100 \mathrm{mM}$ imidazole, respectively, in order to remove any proteins that were unspecific attached to the matrix. Bound EIN $2^{479-1294}$ was eluted from the column by applying a linear gradient of 100-250 mM imidazole. Elution fractions were analysed by SDS-PAGE. Fractions showing the highest purity were pooled, rebuffered in 50 $\mathrm{mM}$ Tris $\mathrm{pH} 7.6,100 \mathrm{mM}$ sodium chloride, concentrated and stored at $4{ }^{\circ} \mathrm{C}$ or $-70^{\circ} \mathrm{C}$, respectively. ETR1 was expressed and purified as described in $[17,18]$

\section{Preparation of tryptophan-less ETR1 and EIN2 $2^{479-1294}$}

Plasmids pET16b-ETR1 [17] and plasmid pET21a_MCSpET28a_EIN2 $2^{479-1294}$ encoding the ethylene receptor protein ETR1 or the C-terminal part of EIN2, respectively, were used for the construction of tryptophan-less mutant proteins. 
Endogenous tryptophan residues at positions 11, 53, 74, 182, 265, 288 and 563 in ETR1 and at positions 622, 682, 812, 948, 1012, 1075, 1129, 1140 and 1158 in EIN2 were substituted either by phenylalanine or leucine by site-directed mutagenesis using sequential PCR steps as described by Cormack [19]. Amplification reactions were carried out using Pfu-polymerase, plasmids pET16b-ETR1 or pET21a_MCSpET28a EIN2 $2^{479-1294}$ as template and mutagenic oligonucleotides listed in Table I (see Supplementary Information). MCS Primer also listed in Table I (see Supplementary Information) were used to amplify the complete fragment encoding ETR1 or EIN2 ${ }^{479-1294}$. The amplified fragments were agarose gel purified, digested with NdeI and BamHI for ETR1 or NheI and EagI for EIN2 and ligated into the equivalent sites of $p E T 16 b$ or $p E T 21 a \_M C S p E T 28 a$. The inserted fragments were sequenced to confirm tryptophan substitutions and absence of additional mutations. Complete substitution of all endogenous tryptophan residues in ETR1 and EIN2 was obtained by the repetitive application of this protocol using the mutagenic primer listed in Table I (see Supplement). The final plasmids containing all tryptophan substitutions were named pET16b-ETR1( $\Delta W)$ and pET21a_MCSpET28a_EIN2 ${ }^{479-1294}(\Delta W)$.

\section{Fluorescence Spectroscopy}

Steady state fluorescence measurements on recombinant proteins were carried out in a Perkin-Elmer LS-55 spectrophotofluorometer at room temperature using an excitation wavelength of $295 \mathrm{~nm}$. Quenching of tryptophan fluorescence of purified wild type ETR1 or wild type EIN2 $2^{479-1294}$ was measured at $345 \mathrm{~nm}$. For the titration, $50 \mu \mathrm{L}$ with increasing concentrations of tryptophan-less protein $\left(0-1 \mu \mathrm{M}\right.$ EIN $2^{479-1294}$ or $0-5 \mu \mathrm{M}$ ETR1, respectively) was added to $450 \mu \mathrm{L}$ of the wild type protein $(0.1 \mu \mathrm{M}$ ETR1 or $0.5 \mu \mathrm{M}$ EIN2 ${ }^{479-1294}$, respectively). Tryptophan-less EIN2 $2^{479-1294}$ was dissolved in a buffer containing $50 \mathrm{mM}$ Tris $\mathrm{pH} 7.6$ and $50 \mathrm{mM}$ sodium chloride; tryptophan-less ETR1 in $50 \mathrm{mM}$ Tris $\mathrm{pH} 7.6,100 \mathrm{mM}$ potassium chloride, $50 \mathrm{mM}$ sodium chloride and $0.1 \%$ (w/v) $\beta$-dodecylmaltoside. Wild type EIN2 was dissolved in $50 \mathrm{mM}$ Tris $\mathrm{pH} 7.6$ and $50 \mathrm{mM}$ sodium chloride; wild type ETR1 in $50 \mathrm{mM}$ Tris $\mathrm{pH}$ 7.6, $100 \mathrm{mM}$ potassium chloride, $50 \mathrm{mM}$ sodium chloride and $0.1 \%(\mathrm{w} / \mathrm{v}) \beta$ dodecylmaltoside. The dissociation constant of the ETR1-EIN2 complex was determined from the fluorescence data using the program GraFit (Erithacus Software Ltd., Surrey, U.K.) by a fit of the experimental data to a model assuming a single binding site in the interacting partners.

\section{Confocal Fluorescence Microscopy}

Confocal Fluorescence Microscopy was performed with a Zeiss LSM 510 Meta Laser Scanning Microscope (Carl Zeiss GmbH, Göttingen, Germany) using a Plan-Neoflur $40 \mathrm{x} / 1.3$ oil immersion objective. The following settings were used throughout the experiments: excitation $488 \mathrm{~nm}$ for GFP, $561 \mathrm{~nm}$ for mCherry, detection wavelength 497-550 $\mathrm{nm}$ for GFP and 583-636 nm for mCherry. Images were recorded and processed using Zeiss LSM 510 Software (Carl Zeiss GmbH). For FRET interaction studies, GFP and mCherry tagged expression vectors encoding for ETR1 and EIN2 were coinfiltrated in $N$. benthamina. FRET was measured with the acceptor bleaching method. The measurements were performed as follows: Images ( $256 \times 256$ pixel, 2.55 $\mu$ sec scan speed/pixel) in the GFP and the mCherry channel were acquired before and after bleaching. The acceptor mCherry was bleached 100 times with 100\% laser power of the $561 \mathrm{~nm}$ diode laser line in a region of interest (ROI). FRET was quantified by measuring GFP fluorescence intensity in the bleached area before ( 5 frames) and after bleaching (15 frames). FRET efficiency (FRET eff $_{\text {f }}$ ) expressed as 
percentage of fluorescence increase was calculated according to the following expression:

$\mathrm{FRET}_{\text {eff }}=\left(\left(I\left[G F P_{\text {after bleaching }}\right]-I\left[G F P_{\text {before bleaching }}\right]\right) / I\left[G F P_{\text {after bleaching }}\right]\right) \times 100$.

\section{Circular Dichroism Spectroscopy}

Circular Dichroism (CD) spectra of the purified carboxyl-terminal domain of EIN2 were recorded in a cylindrical quartz cuvette (path length $1 \mathrm{~mm}$ ) at $20^{\circ} \mathrm{C}$ using a Jasco 715 Spectrophotopolarimeter (Jasco, Groß-Umstadt, Germany). Signals were monitored in a buffer containing $50 \mathrm{mM}$ potassium phosphate $\mathrm{pH} 7.6$ and $50 \mathrm{mM}$ sodium chloride at a protein concentration of $0.1 \mathrm{mg}^{\cdot} \mathrm{ml}^{-1}$. Secondary structure of the purified EIN2 protein was deduced from the spectra using Selcon3 [20] and ContinLL [21].

\section{Protein quantification and polyacrylamide gel electrophoresis}

Protein concentrations were determined by the bicinchoninic acid assay (Pierce Chemicals, Rockford, IL, U.S.A.) using bovine serum albumin as a standard. Purification of ETR1 and EIN2 $2^{497-1294}$ was examined by SDS PAGE as described by Laemmli [22] and Schägger and Jagow [23], respectively. Proteins were separated on $10 \%$ polyacrylamide gels and visualised by silver staining according to Heukeshoven and Dernick [24]. 


\section{RESULTS AND DISCUSSION}

\section{Intracellular localisation of the membrane protein EIN2}

To examine the intracellular localisation of EIN2, a full-length form of EIN2 fused to GFP at the C-terminal end was constructed and transiently expressed in Nicotiana benthamiana. Expression of the fluorescent EIN2 fusion protein was analysed by confocal microscopy. As shown in Figure 1A the characteristic net-like pattern of the endoplasmic reticulum membrane system was observed in the tobacco epidermal leaf cells. Identity of the stained pattern and the intracellular ER network was demonstrated by co-expression of the mCherry-labelled ER marker protein ER-Rb (Figure 1B) and the EIN2-GFP fusion protein. The perfect overlay of both expression pattern shown in Figure $1 \mathrm{C}$ demonstrated co-localisation of both proteins and verified localisation of EIN2 at the ER membrane. Staining of the nucleus by the fluorescent probe 4',6-diamidino-2-phenylindole dihydrochloride (DAPI) was used to analyse whether EIN2 is also targeted to the nuclear membrane. Analysis of the DAPI and the GFP-fluorescence signals shown in Figure 1 D-E suggests that it was unlikely that EIN2-GFP also localises to the nucleus which was exclusively stained by DAPI but showed no GFP fluorescence. In summary our localisation study provides the first experimental evidence that a central component of the ethylene signalling pathway the membrane protein EIN2 - localises to the ER endomembrane system in plant cells. Other components of the ethylene signalling cascade like the ethylene receptor family and the soluble Raf-like kinase CTR1 have been also localised at the ER in previous studies [7-9]. Hence, signalling of the plant hormone might employ a ERborne ternary super-complex (e.g., ETR1-CTR1-EIN2) or a binary complex formed by the receptor proteins and EIN2 (e.g., ETR1-EIN2).

\section{Detection of EIN2-ETR1 interactions via FRET microscopy}

Interaction of EIN2 with the ethylene receptor ETR1 was probed by Fluorescence Resonance Energy Transfer (FRET) using the fluorophors GFP as donor and mCherry as acceptor. The acceptor fluorophor was fused to the C-terminus of EIN2 while the donor was attached to the C-terminus of ETR1. $N$. benthamiana epidermal leaf cells were co-transformed with both vector constructs and expression of both fusion proteins was induced by the addition of $\beta$-Estradiol. Upon simultaneous excitation of doubly labelled cells at $488 \mathrm{~nm}$ and $561 \mathrm{~nm}$ both GFP and mCherry showed strong fluorescence. Energy transfer between both fluorophors and thus in planta interaction between ETR1 and EIN2 was demonstrated by the acceptor bleaching method [25] and is shown in Figure 2 A-B. From the increase in GFP fluorescence upon acceptor bleaching an overall FRET efficiency of $18.3+/-2.3 \%$ is estimated. Similar transfer efficiencies were obtained in experiments studying the interaction of human TNFReceptor-Associated-Factors by FRET spectroscopy [25]. Control experiments using tandem labelled ETR1 show a transfer efficiency of $16.2+/-2.5 \%$. Background fluctuations measured with ETR1-GFP are $3.5+/-1.2 \%$. Specificity of the EIN2ETR1 interaction was addressed in controls expressing ETR1-GFP and mCherry labelled ER marker protein. A transfer efficiency of only $2.9+/-0.6 \%$ was observed in this control which is considerably lower than the FRET-efficiency found in cells expressing ETR1-GFP and EIN2-mCherry. Successful expression of all fusion proteins used in this study in the tobacco leaf cells was verified by monitoring fluorescence of the respective marker (GFP/mCherry) at the appropriate wavelength (see Supplemental Figure 2). 
The FRET efficiency observed for the ETR1-GFP:EIN2-mCherry donor:acceptor pair in our experiments $(18.3+/ 2.3 \%)$ was used to estimate the separation distance of the related protein-protein complex. Using a Förster distance of $5.1 \mathrm{~nm}$ for the GFP:mCherry donor-acceptor pair [26] a separation distance of $6.5 \mathrm{~nm}$, with a range between $6.4 \mathrm{~nm}$ and $6.7 \mathrm{~nm}$, was calculated from these numbers assuming random orientation of dipole moments. This figure is clearly in the range that can be expected for an ETR1:EIN2 complex assuming an average diameter of $0.465 \mathrm{~nm}$ per transmembrane helix [27] and a sequence based number of 12 TMH for EIN2 and of $3 \mathrm{TMH}$ for ETR1, i.e. $15 \mathrm{TMH}$ or $7 \mathrm{~nm}$ in total. However, the distance fundamentally depends on the arrangement of the TMH in the membrane as well as on the orientation of the C-termini of EIN2 and ETR1 carrying the acceptor and donor fluorophor relative to their TM domain. Furthermore, environment, orientation or movement of the fluorophors are not known for the plant system. The FRET efficiency of $18 \%$ obtained for the ETR1-GFP:EIN2-mCherry donor:acceptor pair is in clear contrast to background fluctuations and negative controls that are in the range of about 3\%. Furthermore, even in a controlled in vitro system only a maximum FRET efficiency of $35 \%$ was detected for the GFP:mCherry pair [26]. Hence, we conclude that the FRET observed for the co-expressed ETR1-GFP and EIN2mCherry fusions is mediated by a specific interaction of EIN2 and ETR1 rather than by non-specific binding of the overexpressed fluorescent probes.

In order to quantify the interaction of EIN2 and ETR1 revealed by FRET in the in planta studies we have applied fluorescence titration studies using recombinant proteins. In these studies we employed a tryptophan-less mutant of ETR1 for titration of wild-type EIN2 and the other way round a tryptophan-less mutant of EIN2 for titration of wild-type ETR1.

To determine whether the substitution of the endogenous tryptophan residues in ETR1 led to significant changes in the protein structure, folding and secondary structure of wild type and tryptophan-less mutant protein were checked by CDspectroscopy. Wild type and mutant protein showed similar spectra. Autokinase activity of the recombinant proteins measured by the incorporation of radioactive labelled $\left[\gamma-{ }^{32} \mathrm{P}\right] \mathrm{ATP}$ also clearly demonstrated that the tryptophan-less ETR1 protein retained wild type characteristics (data not shown).

Cloning, Expression and Purification of the C-terminal domain of EIN2 in E.coli The C-terminal part of EIN2 representing the putative membrane-extrinsic region of the receptor was amplified from a cDNA library obtained from etiolated seedlings of Arabidopsis thaliana and cloned into a modified pET21a vector containing aminoterminal and C-terminal hexahistidine-tags. Induction of E. coli BL21(DE3) pET21a_MCSPET28a_EIN2 $2^{479-1294}$ by addition of IPTG resulted in production of recombinant EIN2 protein in soluble form (Figure 3A). Expression of EIN2 was confirmed by anti-His antibodies (Figure 3B). Over-expressed recombinant EIN2 was purified to homogeneity from $E$. coli cells extracts by metal-chelate affinity chromatography using a Ni-IDA Superflow column. A single band on silver-stained SDS-PAGE confirmed purity and homogeneity of the protein (Figure 3C). By this procedure approximately $1 \mathrm{mg}$ purified protein was routinely obtained from 11 cell culture. Similar amounts were obtained with the tryptophan-less EIN2 mutant protein.

\section{Circular Dichroism Analysis of recombinant EIN2}

Folding and secondary structure composition of recombinant wild type and tryptophan-less EIN2 $2^{479-1294}$ was estimated using CD spectroscopy. Wild type and 
mutant protein showed similar spectra. The observed minima at $206 \mathrm{~nm}$ and $220 \mathrm{~nm}$ (see Supplementary Figure 1) indicate of predominately $\alpha$-helical structure of the EIN2 protein. Secondary structure calculations using Selcon3 and ContinLL, two different algorithms for estimation of secondary structure composition of an unknown CD spectrum, yielded an $\alpha$-helix content of $39 \%$ and a $\beta$-sheet percentage of 11-13 $\%$ for the recombinant protein. Both data agree with the numbers predicted from the primary structure of the carboxyl-terminal of EIN2 using the program PROF $[28,29]$ which are $46 \% \alpha$ helix and $10 \% \beta$-sheet. In summary the circular dichroism analysis demonstrates that the recombinant EIN2 protein adopts a well folded structure which is likely to reflect the natural structure of the protein. Furthermore, the agreement of CD-data obtained with wild type and tryptophan-less EIN2 indicate that folding and structure of the tryptophan-less mutant protein were not perturbed.

\section{Fluorescence titration studies of ETR1 and EIN2}

The intrinsic fluorescence of proteins is dominated by the emissions from tryptophan residues and tryptophan fluorescence provides a sensitive intrinsic probe to study changes in the local environment of a protein, e.g., caused due to the interaction of the protein with any other small or large molecule. In order to use tryptophan fluorescence as a sensitive tool to study protein-protein interactions all endogenous tryptophan residues have to be removed from one of the proteins involved in the formation of the binary complex. Quenching of tryptophan fluorescence upon addition of the tryptophan-less binding partner can be used to evaluate the stability of the interaction and to determine the apparent dissociation constant of the complex.

When wild type EIN2 was titrated with the tryptophan-less ETR1 mutant a $\mathrm{K}_{d}$ of 360 $\mathrm{nM}$ was obtained (see Figure 4A), while titration of ETR1 by a tryptophan-less EIN2 mutant resulted in a slightly higher $K_{d}$ of $440 \mathrm{nM}$ as shown in Figure 4B. Taken together both studies underline that ETR1 and EIN2 form a highly specific interaction.

The fluorescence titration measurements performed in this study using recombinant wild-type and tryptophan-less proteins provide for the first time a quantitative understanding on a protein-protein interaction in the ethylene signalling cascade. The measurements require only small amounts of the recombinant proteins $\left(10^{-6} \mathrm{M}\right.$ range $)$ and allow an exact control of the external parameter. They have the potential to narrow down the interacting domains in both proteins and to address the stability of the complex in response to ethylene or ethylene antagonists in future experiments.

In summary the localisation and interaction studies presented in this work define a new interaction within the ethylene signalling cascade. Together with studies from other labs [7-9] they suggest that ethylene signalling might employ an ER-borne signalling complex consisting of ethylene receptor proteins (ERP) and EIN2 or an even more complex structure containing ETR1, CTR1 and EIN2.

\section{ACKNOWLEDGEMENTS}

We thank Rüdiger Simon for stimulating discussion and helpful advice on the EIN2 localisation studies. We also thank Elisa Buchen for assistance with the CDmeasurements and Daniel Schlieper for critical reading of the manuscript. This work was supported by the Deutsche Forschungsgemeinschaft within the SFB 590 "Inhärente und adaptive Differenzierungsprozesse" at the Heinrich-Heine-Universität Düsseldorf. 


\section{FIGURE LEGENDS}

\section{Figure 1 SUBCELLULAR LOCALISATION OF EIN2 TRANSIENTLY EXPRESSED IN N. BENTHAMIANA EPIDERMAL LEAF CELLS}

Confocal laser scanning microscopy images of representative $N$. bethamiana cells showing fluorescence of (A) EIN2-GFP, (B) ER-Rb marker protein. GFP (497-550 $\mathrm{nm})$ and mCherry channels $(572-637 \mathrm{~nm})$ were scanned simultaneously. (C) Merged images. (D) DAPI staining of the nucleus monitored at 420-480 nm. (E) EIN2-GFP fluorescence reflecting the typical ER network structure surrounding the nucleus. Images for DAPI and EIN2-GFP were monitored separately to avoid crosstalk between both channels. (F) Merged images. Excitation wavelength was $405 \mathrm{~nm}$ for DAPI, $488 \mathrm{~nm}$ for GFP and $561 \mathrm{~nm}$ for mCherry.

\section{FIGURE 2 FRET REVEALS IN PLANTA INTERACTION OF EIN2 AND ETR1}

(A) Images of $N$. benthamiana cells before (upper panel) and after (lower panel) mCherry photobleaching. Both, ETR1-GFP fluorescence (Left panel) and EIN2mCherry signal (Right panel) are shown. Photobleaching of mCherry results in an increase of the ETR1-GFP signal. (B) FRET efficiency was estimated from GFP recovery after photobleaching of mCherry. Cells co-expressing EIN2-mCherry and ETR1-GFP show an increase in transfer efficiency of $18.3+/-2.3 \%$. Background fluctuations in GFP fluorescence measured in cells expressing ETR1-GFP on its own are $3.5+/-1.2 \%$. Controls expressing a tandem construct of ETR1 labelled with GFP and mCherry show a FRET efficiency of $16.2+/-2.5 \%$. Coexpression of ETR1-GFP and the mCherry labelled ER marker protein showed transfer efficiencies of $2.9+/-$ $0.6 \%$. FRET efficiency, was calculated as the difference between GFP fluorescence after and before the bleach, normalized by the fluorescence after the bleach (see EXPERIMENTAL). Microscope and laser settings are described in EXPERIMANTAL. Expression of fusion proteins was verified by detecting an emission signal in the GFP channel for ETR1-GFP and in the mCherry channel for other fusions, respectively (for details see RESULTS AND DISCUSSION and SUPPLEMENTARY FIGURE 2)

\section{Figure 3 EXPRESSION AND PURIFICATION OF EIN2 ${ }^{479-1294}$}

E. coli BL21(DE3) was transformed with the pET21a_MCSpET28a_EIN2 $2^{479-1294}$ expression plasmid. Expression was started with $0.5 \mathrm{mM}$ IPTG. Extracts from the host cells expressing EIN2 ${ }^{479-1294}$ were analysed by $10 \%$ SDS-PAGE and Western blotting. The protein was tagged with both N-terminal and C-terminal hexahistidine tags for purification by immobilized metal chelate chromatography. A, SDS-PAGE of whole cell extracts. Fractions were analyzed $6 \mathrm{~h}$ after expression either in the absence of inductor (lane 1) or in the presence of $0.5 \mathrm{mM}$ IPTG (lane 2). Sizes of molecular mass standards (lane 3) are indicated. EIN2 ${ }^{479-1294}$ migrates on SDS gels with an apparent molecular mass of $98 \mathrm{kD}$ somewhat larger than the calculated size $(92 \mathrm{kD})$. B, Expression was confirmed by Western blotting using anti-His antibodies. Lane 1, cell lysate, lane 2, cell lysate induced with $0.25 \mathrm{mM}$ IPTG, lane 3 protein marker. C, Silver-stained SDS-PAGE of EIN2 $2^{479-1294}$ after purification on Ni-IDA. Lane 1 protein marker, lanes 2-4 $0.2,2$ and $5 \mathrm{mg}^{\cdot} \mathrm{ml}^{-1}$ of purified EIN2 $2^{479-1294}$. 
Figure 4 IN VITRO INTERACTION STUDIES OF EIN2 AND ETR1

Titration of purified recombinant EIN $2^{479-1294}$ with purified recombinant tryptophanless ETR1 (B) and titration of purified recombinant ETR1 with purified recombinant tryptophan-less EIN2 $2^{479-1294}$ (E). Quenching of tryptophan fluorescence in wild type proteins caused by the addition of tryptophan-less mutant proteins was analysed according to Libich et al. [30]. $F_{0}$ corresponds to the initial fluorescence intensities of wild type proteins, $F$ to the fluorescence that is obtained at different concentrations tryptophan-less proteins added. Data were fitted to a model assuming a single binding site in the interacting partners. Dissociation constants ETR1- EIN2 $2^{479-1294}=440 \mathrm{nM}$ $+/-70 \mathrm{nM}\left(\chi^{2}=0.0008781\right)$, dissociation constant EIN2 ${ }^{479-1294}-\mathrm{ETR} 1=360 \mathrm{nM}+/-$ $82 \mathrm{nM}\left(\chi^{2}=0.0039\right)$. Silver-Stained SDS-polyacrylamide gels of purified EIN $2^{479-1294}$ (A), tryptophan-less ETR1 (C), tryptophan-less EIN2 $2^{479-1294}$ (D) and ETR1 (F). 


\section{REFERENCES}

1. Abeles, F.B., Morgan, P.W. and Saltveit, M.E. (1992) Ethylene in Plant Biology. Academic Press, San Diego

2. Johnson, P.R. and Ecker, J.R. (1998) The ethylene gas signal transduction pathway: a molecular perspective. Annu. Rev. Genet. 32, 227-254.

3. Chang, C., Kwok, S.F., Bleecker, A.B. and Meyerowitz, E.M. (1993) Arabidopsis ethylene-response gene ETR1: similarity of product to two-component regulators. Science 262, 539-544.

4. Hua, J., Chang, C., Sun, Q. and Meyerowitz, E.M. (1995) Ethylene insensitivity conferred by Arabidopsis ERS gene. Science 269, 1712-1714.

5. Sakai, H., Hua, J., Chen, Q.G., Chang, C., Medrano, L.J., Bleecker, A.B. and Meyerowitz, E.M. (1998) ETR2 is an ETR1-like gene involved in ethylene signaling in Arabidopsis. Proc. Natl. Acad. Sci. U. S. A. 95, 5812-5817.

6. Hua, J., Sakai, H., Nourizadeh, S., Chen, Q.G., Bleecker, A.B., Ecker, J.R. and. Meyerowitz, E.M (1998) EIN4 and ERS2 are members of the putative ethylene receptor gene family in Arabidopsis. Plant Cell 10, 1321-1332.

7. Chen, Y.F., Randlett, M.D., Findell, J. L. and Schaller, G.E. (2002) Localization of the ethylene receptor ETR1 to the endoplasmic reticulum of Arabidopsis. J. Biol. Chem. 277, 19861-19866.

8. Grefen, C., Städele, K., Růžička, K., Obrdlik, P., Harter, K. and Horák, J. (2008) Subcellular Localization and In Vivo Interactions of the Arabidopsis thaliana Ethylene Receptor Family Members Mol. Plant 1, 308-320.

9. Gao, Z., Chen, Y.F., Randlett, M.D., Zhao, X.C., Findell, J.L., Kieber, J.J. and Schaller G.E. (2003) Localization of the Raf-like kinase CTR1 to the endoplasmic reticulum of Arabidopsis through participation in ethylene receptor signaling complexes. J. Biol. Chem. 278, 34725-34732.

10. Kieber, J.J., Rothenberg, M., Roman, G., Feldmann, K.A. and Ecker, J.R. (1993) CTR1, a negative regulator of the ethylene response pathway in Arabidopsis, encodes a member of the raf family of protein kinases. Cell 72, 427-441.

11. Alonso, J.M., Hirayama, T., Roman, G., Nourizadeh, S. and Ecker, J.R. (1999) EIN2, a bifunctional transducer of ethylene and stress responses in Arabidopsis. Science 284, 2148-2152.

12. Qiao, H., Chang, K.N., Yazaki, J. and Ecker J.R. (2009) Interplay between ethylene, ETP1/ETP2 F-box proteins, and degradation of EIN2 triggers ethylene responses in Arabidopsis. Genes Dev. 23, 512-521.

13. Curtis, M. and Grossniklaus, U. (2003) A gateway cloning vector set for highthroughput functional analysis of genes in planta. Plant Physiology 133, 462-469.

14. Nelson, B.K., Cai, X. and Nebenführ, A. (2007) A multicolored set of in vivo organelle markers for co-localization studies in Arabidopsis and other plants. Plant J. 51, 1126-36

15. Koncz, C. and Schell, J. (1986) The promoter of TL-DNA gene 5 controls the tissue-specific expression of chimaeric genes carried by a novel type of Agrobacterium binary vector Mol Gen Genet 204, 383-396

16. Voinnet, O., Rivas, S., Mestre, P., and Baulcombe, D. (2003) An enhanced transient expression system in plants based on suppression of gene silencing by the p19 protein of tomato bushy stunt virus. Plant J. 33, 949-956.

17. Voet-van-Vormizeele, J. and Groth, G. (2003) High-level expression of the Arabidopsis thaliana ethylene receptor protein ETR1 in Escherichia coli and purification of the recombinant protein. Protein Expr. Purif. 32, 89-94. 
18. Scharein, B., Voet van Vormizeele, J., Harter, K. and Groth, G. (2008) Ethylene signalling: Identification of a putative ETR1-AHP1 phosphorelay complex by fluorescence spectroscopy. Anal. Biochem. 377, 7276.

19. Cormack, B. (1992) Site directed mutagenesis by the polymerase chain reaction. in Short protocols in Molecular Biology (Struhl, K. ed.) pp 8-18 - 8-25, John Wiley \& Sons, New York.

20. Sreerama, N. and Woody, R.W. (1993) A self-consistent method for the analysis of protein secondary structure from circular dichroism. Anal. Biochem. 209, 3244.

21. Provencher, W. and Glockner, J. (1981) Estimation of globular protein secondary structure from circular dichroism. Biochemistry 20, 33-37.

22. Laemmli, U.K. (1970) Cleavage of structural proteins during the assembly of the head of bacteriophage T4. Nature 227, 680-685.

23. Schägger, H. and von Jagow, G. (1987) Tricine-sodium dodecyl sulfatepolyacrylamide gel electrophoresis for the separation of proteins in the range from 1 to $100 \mathrm{kDa}$. Anal. Biochem. 166, 368-379.

24. Heukeshoven, J. and Dernick, R. (1988) Improved silver staining procedure for fast staining in PhastSystem Development Unit. I. Staining of sodium dodecyl sulfate gels. Electrophoresis 9, 28-32.

25. Karpova, T.S., Baumann, C.T., He, L., Wu, X., Grammer, A., Lipsky, P., Hager, G.L. and McNally, J.G. (2003) Fluorescence resonance energy transfer from cyan to yellow fluorescent protein detected by acceptor photobleaching using confocal microscopy and a single argon laser. J. Microscopy 209, 56-70.

26. Albertazzi, L., Arosio, D., Marchetti, L., Ricci, F., and Beltram, F. (2008) Quantitative FRET analysis with the EGFP-mCherry Fluorescent Protein Pair. Photochemistry and photobiology 85, 287-297.

27. Bolterauer, H. and Henkel, R.D. (1986) Solitons in the Alpha-Helix. Physica Scripta T13, 314-318.

28. Rost, B. and Sander, C. (1993) Prediction of protein secondary structure at better than 70\% accuracy. J. Mol. Biol. 232, 584-599.

29. Rost, B., Fariselli, P. and Casadio, R. (1996) Topology prediction for helical transmembrane proteins at 86\% accuracy Protein Sci. 7, 1704-1718.

30. Libich, D.S., Hill, C.M.D., Bates, I.R., Hallett, F.R., Armstrong, S., Siemiarczuk, A. and Harauz, G. (2003) Interaction of the $18.5-\mathrm{kD}$ isoform of myelin basic protein with $\mathrm{Ca}^{2+}$-calmodulin: effects of deimination assessed by intrinsic Trp fluorescence spectroscopy, dynamic light scattering, and circular dichroism. Protein Sci. 12, 1507-1521. 
B Biochemical Journal Immediate Publication. Published on 21 Sep 2009 as manuscript BJ20091102

\section{FIGURE 1}

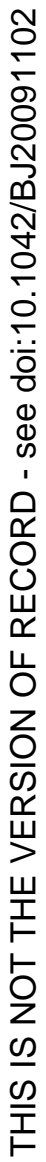

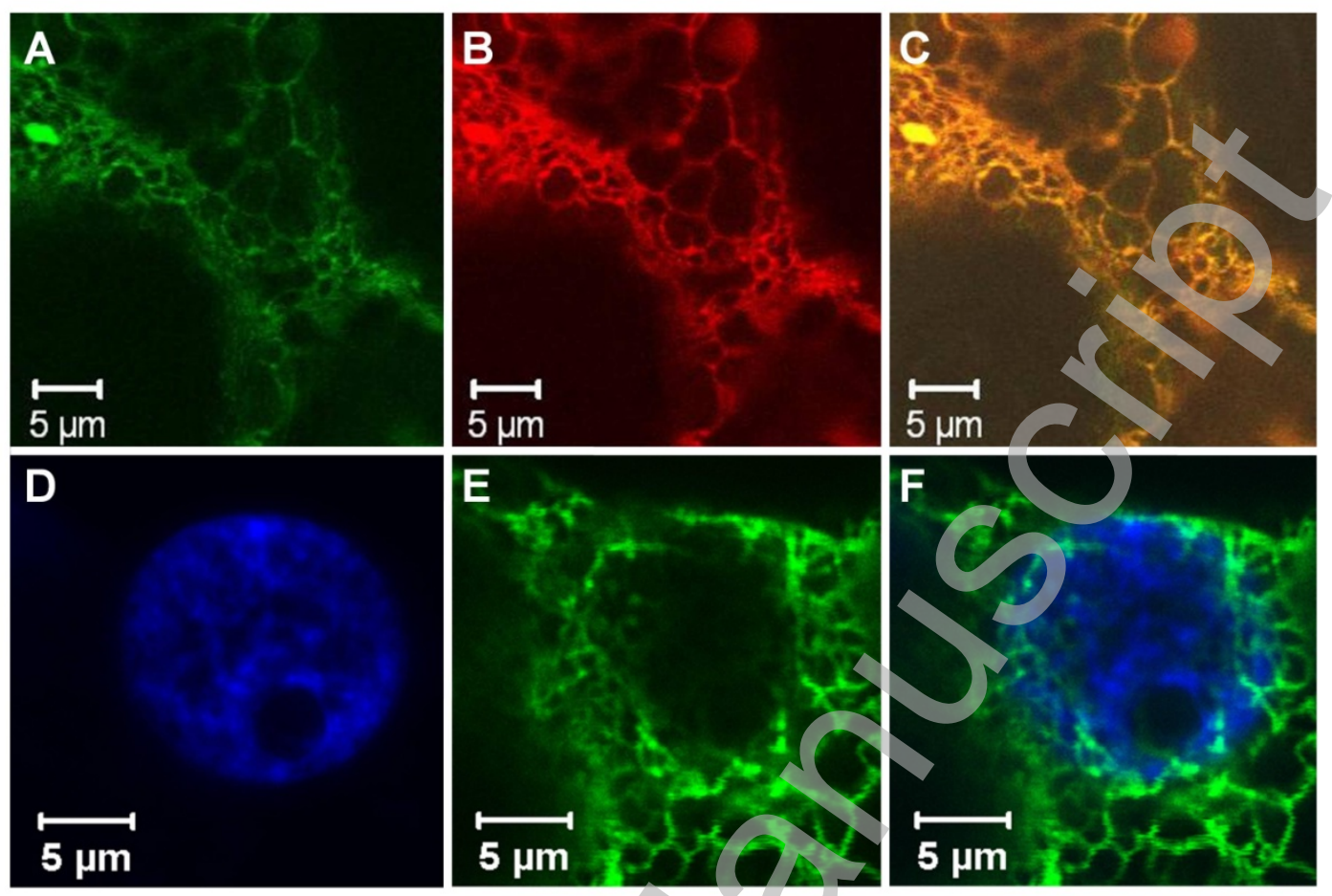


Biochemical Journal Immediate Publication. Published on 21 Sep 2009 as manuscript BJ20091102

\section{FIGURE 2}

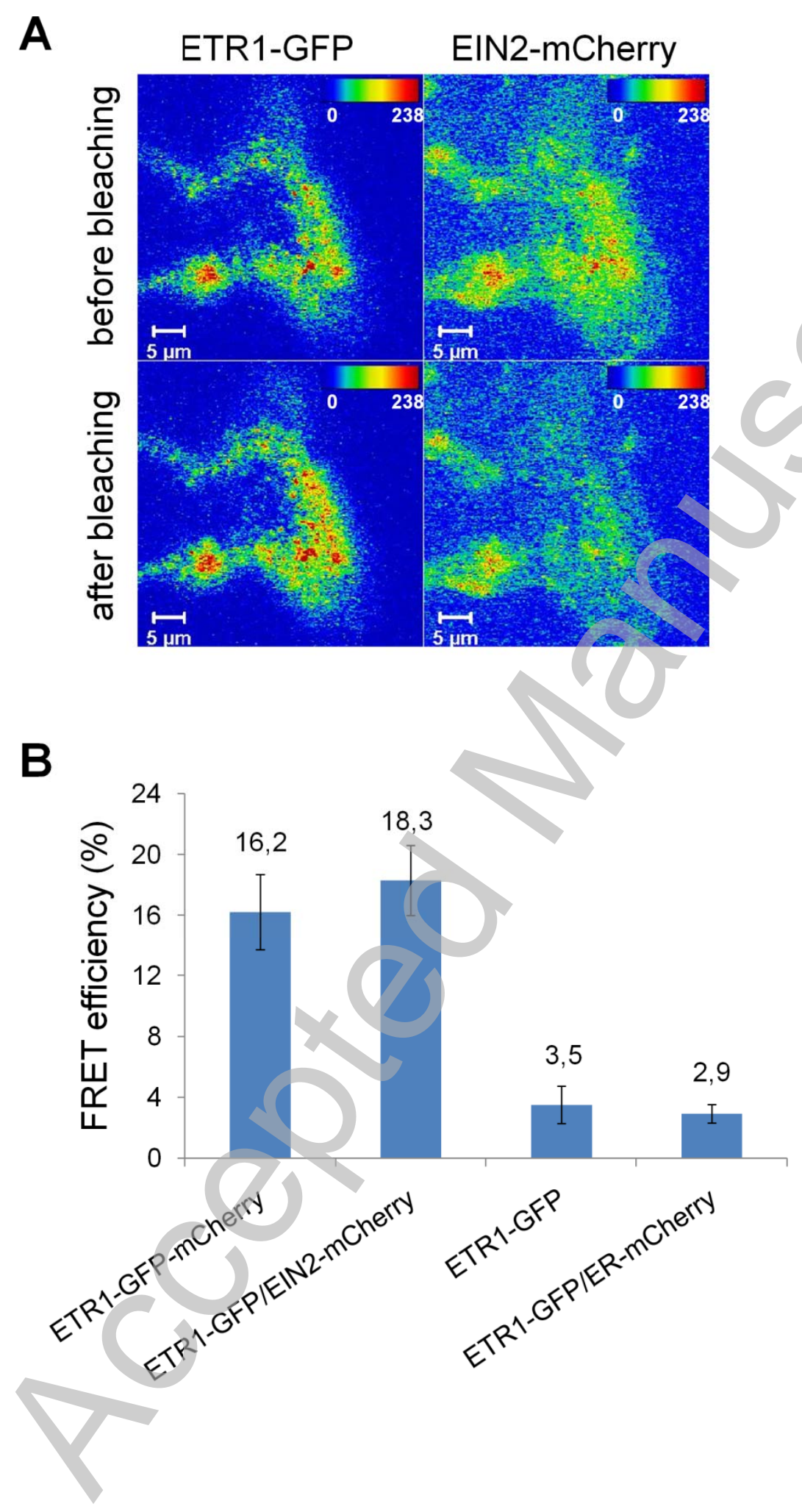




\section{FIGURE 3}

A

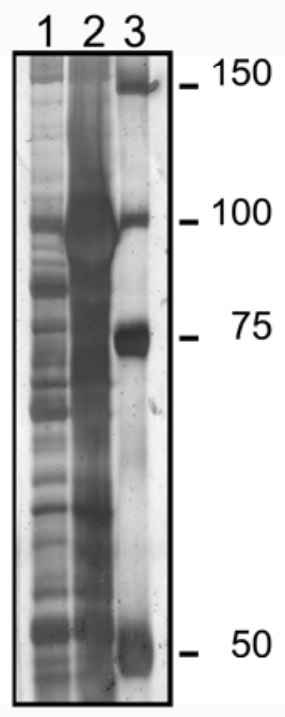

B

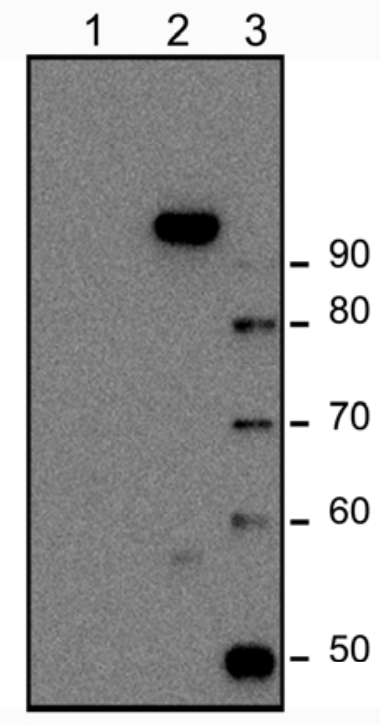

C

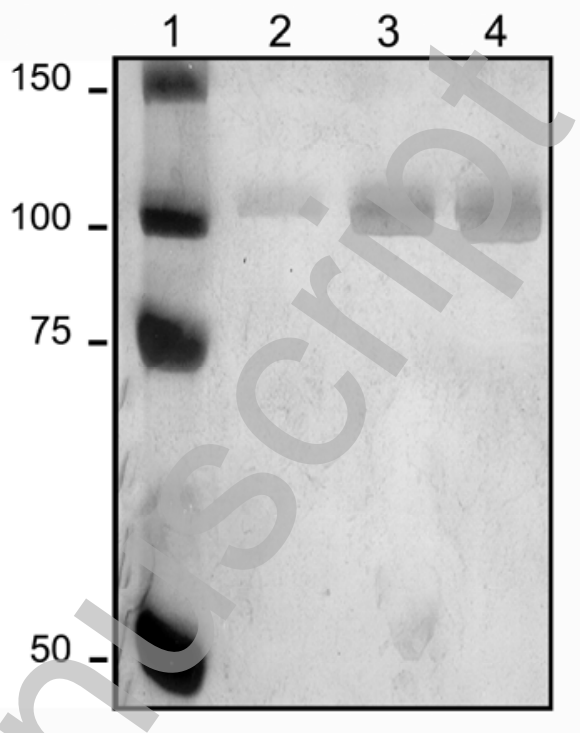




\section{FIGURE 4}

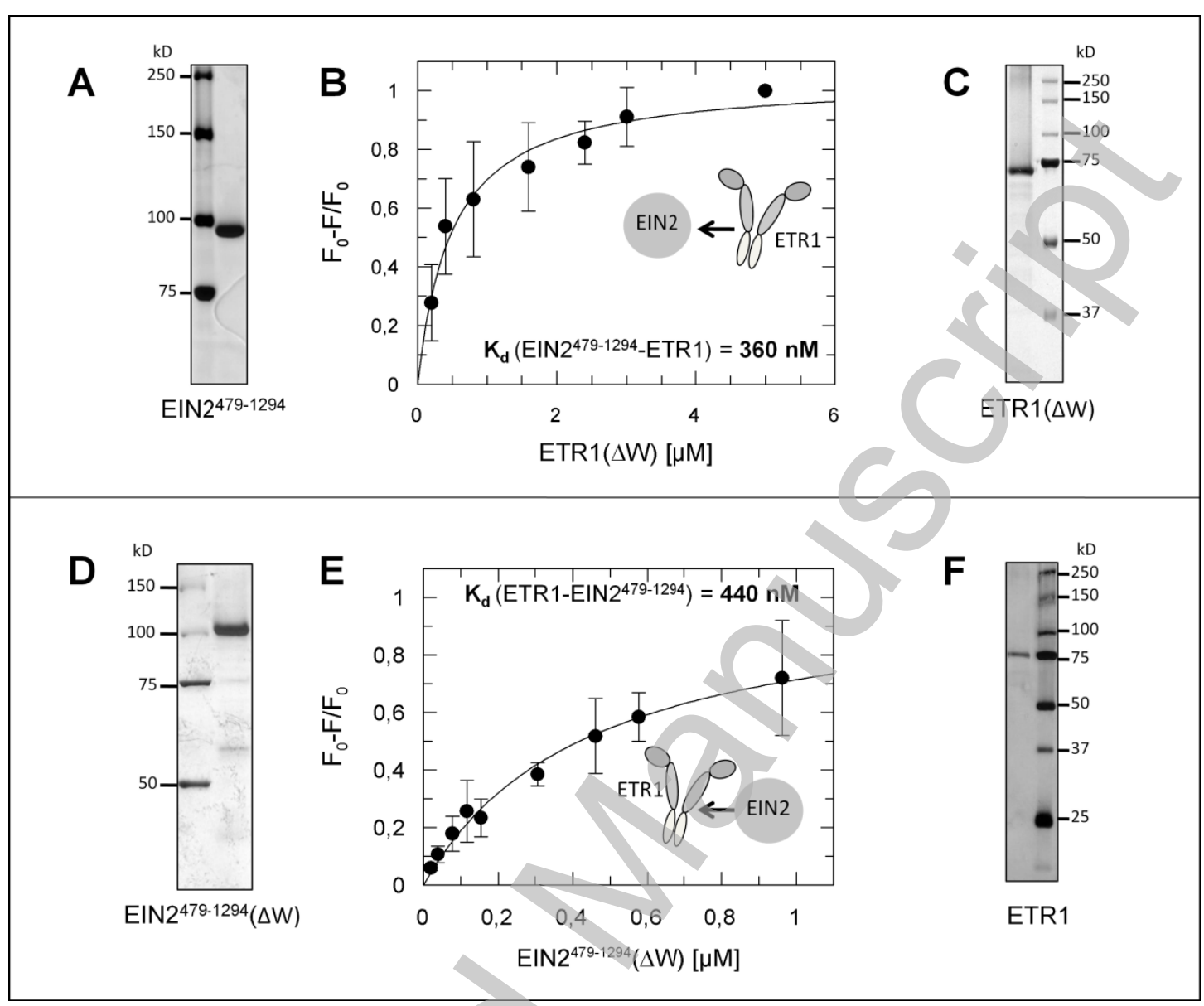

